\title{
Pituitary response to luteinizing hormone-releasing hormone in women with variant luteinizing hormone
}

\author{
Kentaro Takahashi, Hiroko Kurioka, Tomoya Ozaki, Haruhiko Kanasaki, Kohji Miyazaki and Kenji Karino ${ }^{1}$ \\ Department of Obstetrics and Gynecology and ${ }^{1}$ Central Clinical Laboratory, Shimane Medical University, Izumo 693-8501, Japan \\ (Correspondence should be addressed to K Takahashi, Department of Obstetrics and Gynecology, Shimane Medical University, 89-1, Enya-cho, \\ Izumo 693-8501, Japan; Email: taka27@shimane-med.ac.jp)
}

\begin{abstract}
Objective: To assess the LH response of the pituitary gland to GnRH stimulation in healthy women with a mutant $\beta$-subunit (Trp8 to Arg8 and Ile15 to Thr15).

Design: Clinical study.

Patients: We studied 40 healthy non-pregnant Japanese women of known zygosity for the LH $\beta$-subunit gene ( 3 homozygotes for the mutant gene, 17 heterozygotes, and 20 homozygotes for the wild type). All women had normal ovulatory cycles.

Measurements: Serum LH status was determined by comparing LH immunoassays results using a monoclonal antibody recognizing only wild-type LH with those from a polyclonal antibody assay recognizing both variant and wild-type LH. The ratio of monoclonal to polyclonal immunoassay results determined the serum LH status. LH secretion in response to a GnRH stimulation test was measured. Results: All women with the wild-type LH showed a normal response of LH to GnRH according to both assays. Over the time course of the response, the ratios in women with wild-type LH showed no remarkable changes. The response curves in women heterozygous for the mutant peaked 15-30 min after GnRH injection; their response patterns included a statistically significant decrease in the rates of response at $15 \mathrm{~min}$ after injection.

Conclusions: There are the differences in circulatory kinetics between the two LH forms and in regulation of the two types of $\mathrm{LH} \beta$ genes. The maximal response of the variant LH to pituitary stimulation with GnRH appears to be greater than that of wild-type LH.
\end{abstract}

European Journal of Endocrinology 143 375-381

\section{Introduction}

In women, luteinizing hormone (LH) promotes ovulation and luteinization of the ovarian follicle and enhances production of steroid in the ovaries. The clinical consequences of reduced LH secretion include anovulation or luteal insufficiency, leading to menstrual disorders and infertility. Recently, several investigators have reported a variant LH $(1-3)$ with two point mutations in the gene coding for its $\beta$-subunit, indicating two amino acid replacements: Trp8 (TGG) to Arg8 (CGG) and Ile15 (ATC) to Thr15 (ACC). A survey of the frequency of the $\mathrm{LH} \beta$ variant in various populations has revealed that it is an ubiquitous polymorphism occurring in $7.1-41.9 \%$ of individuals in healthy populations (4). In our previous study (5), the $\mathrm{LH} \beta$ variant was detected in $8.5 \%$ of healthy, fertile Japanese women. A relationship has been suggested between mutations in the LH $\beta$-subunit and delayed pubertal maturation (6), disorders of the menstrual cycle (1), polycystic ovary syndrome (PCOS) with obesity (7), and infertility (1). We have observed relationships between the variant $\mathrm{LH}$ and infertility, including ovulatory disorders, luteal insufficiency, delayed ovulation, hyperprolactinemia and hyperandrogenemia, and premature ovarian failure $(5,8)$.

However, many unclear areas remain with respect to the clinical, physiologic, and pathophysiologic significance of the variant LH. In this study the pathophysiology of pituitary-gonadal function in women with a variant LH $\beta$-subunit was investigated.

\section{Materials and methods}

\section{Participants}

Forty healthy non-pregnant Japanese women consented to participate in this study. Their ages varied from 22 to 39 years (means \pm s.D., $29.3 \pm 4.3$ years). Women believed to have a pituitary disorder and PCOS, as judged by basal body temperature records, measurements of serum estradiol and progesterone concentrations, and serial transvaginal ultrasonic examinations of the ovaries, were excluded from the study. All women had normal ovulatory cycles. 
In these 40 women, a sequence analysis of the LH $\beta$ subunit gene was performed as described below, identifying three who were homozygous for mutant LH $\beta$-subunit, 17 who were heterozygous, and 20 who were homozygous for the wild-type subunit. Peripheral blood was taken at baseline and at 15, 30, 60, 90 and $120 \mathrm{~min}$ after i.v. injection of $100 \mu \mathrm{g}$ gonadotropinreleasing hormone (GnRH; the GnRH test) on days 3-6 after the onset of menstruation. Serum was separated from blood cells and kept at $-30{ }^{\circ} \mathrm{C}$ until required for analysis. Appropriate University Hospital Committee permission was obtained for the sample-collection protocol.

\section{DNA amplification and sequencing analysis of the $L H \beta$ gene}

Genomic DNA was isolated from peripheral blood lymphocytes using Sepa Gene nucleic acid isolation reagents (Sanko Junyaku, Tokyo, Japan) and was used directly as a polymerase chain reaction (PCR) template.

A portion of the $\mathrm{LH} \beta$ gene was amplified with a 5 primer (5'-GGG AAT TCT CTT TGT GGG TGG TGT ACC ACG C-3') and a $3^{\prime}$ primer (5'-GGA GGA TCC GGG TGT CAG GGC TCC A-3'), to span exon 2 , intron 2 , and exon 3 of the LH $\beta$ gene (2). Underlines indicate introduced restriction enzyme sites for EcoRI and BamHI respectively. The $50 \mu \mathrm{l}$ PCR reaction mixture contained $0.2 \mathrm{mmol} / \mathrm{l}$ of dNTPs, $12.5 \mathrm{pmol}$ of a set of primers, and 1.25 units Ex Taq polymerase (Takara, Kyoto, Japan). After an initial denaturation at $94^{\circ} \mathrm{C}$ for $5 \mathrm{~min}$, 30 cycles of $94^{\circ} \mathrm{C}$ for $1 \mathrm{~min}$ and $68^{\circ} \mathrm{C}$ for 4 min were performed, and final extension was carried out at $68^{\circ} \mathrm{C}$ for $7 \mathrm{~min}$ in a GeneAmp PCR system (Model 2400; Perkin-Elmer, Norwalk, CT, USA).

To distinguish between homozygotes and heterozygotes, PCR direct sequencing was performed. The amplified products (approximately $800 \mathrm{bp}$ ) were purified by microspin column (S-400 HR; Pharmacia, Uppsala, Sweden) and the DNA sequence was determined using $5^{\prime}$ and $3^{\prime}$ primers on an automated DNA sequencer (Model 373S; Perkin-Elmer. Norwalk, CT, USA).

Frequencies of DNA substitutions were determined by DNA sequence analysis of PCR products after cloning to a pUC18 vector. The products, digested with restriction enzymes EcoRI and BamHI, were ligated into pUC18 vector, and 10 positive clones were sequenced with universal primers.

\section{Immunoassay of serum LH}

Two commercial immunoassay kits were used for serum LH detection. One was the SPAC-S LH Kit from Daiichi Radioisotope Laboratory (Tokyo, Japan), which uses an immunoradiometric method (9) and two different monoclonal antibodies that react with the $\beta$-subunit of LH and intact LH dimer respectively. The other was a solid-phase two-site sequential chemiluminescent enzyme immunometric assay kit (Immulyze LH; Nippon DPC Corporation, Chiba, Japan) using an alkaline phosphatase-conjugated polyclonal antibody and a monoclonal antibody specific for LH (10). Samples with LH concentrations less than $0.2 \mathrm{mIU} / \mathrm{ml}$ (conversion factor to SI units, 1.00) by Immulyze were excluded from the study. The SPAC-S assay recognizes only wild-type LH, whereas the Immulyze assay recognizes both variant and wild-type LH (11). The ratio of respective LH values as measured by the two assays (LH ratio: SPAC-S/ Immulyze) was used to assess the variant or wild-type LH status. The percent increase in LH values as measured by the two assays after GnRH stimulation was also calculated to evaluate the changes in absolute variant LH value. The sensitivity of the Immulyze procedure was $0.14 \mathrm{mIU} / \mathrm{ml}$, and intra-assay and interassay coefficients of variation were $<7 \%$ and $8 \%$ respectively. World Health Organization First International Reference Preparation-LH 68/40 was supplied as a reference standard for LH in the immunoassay kits.

The Immulyze method shows a $0.4 \%$ cross-reactivity with human chorionic gonadotrophin (hCG), while SPAC-S does not recognize this hormone $(<0.001 \%$ cross-reactivity).

\section{Statistical analysis}

The data are expressed as the means \pm S.D. The data were analyzed using analysis of variance (ANOVA), Sheffé's F test, the Kolmogorov-Smirnov two-sample test, or the Wilcoxon matched-pairs signed-ranks test. $P<0.05$ was considered significant.

\section{Results}

\section{Hormonal profiles with respect to mutant $\mathrm{LH}$}

In the three women homozygous for the mutant LH $\beta$ subunit, LH was undetectable in serum by SPAC-S $(<0.1 \mathrm{mIU} / \mathrm{ml})$, but was evident by the Immulyze test (LH concentrations of 6.3, 7.6 and $7.8 \mathrm{mIU} / \mathrm{ml}$ ). Serum concentrations (means \pm S.D.) of LH as measured with Immulyze was $7.2 \pm 0.8 \mathrm{mIU} / \mathrm{ml}$ in homozygotes for mutant LH $\beta$-subunit, $6.4 \pm 1.7 \mathrm{mIU} / \mathrm{ml}$ in heterozygotes and $5.8 \pm 1.8 \mathrm{mIU} / \mathrm{ml}$ in homozygotes for the wild-type LH $\beta$-subunit, without statistically significant differences between the three. However, the mean concentration of LH as measured with SPAC-S $(2.2 \pm 0.6 \mathrm{mIU} / \mathrm{ml})$ in the heterozygous group was significantly lower $(P<$ $0.0001)$ than that in the wild-type LH group $(5.4 \pm 1.6 \mathrm{mIU} / \mathrm{ml})$. Twenty women had only the wildtype LH $\beta$-subunit, with LH ratios ranging from 0.80 to $1.06(0.93 \pm 0.08)$. In 17 women heterozygous for the mutant LH $\beta$-subunit, the LH ratio ranged from 0.20 to $0.49(0.35 \pm 0.02)$. The mean LH ratio in the heterozygous group was significantly lower $(P<0.0001)$ than that in the wild-type LH group. 


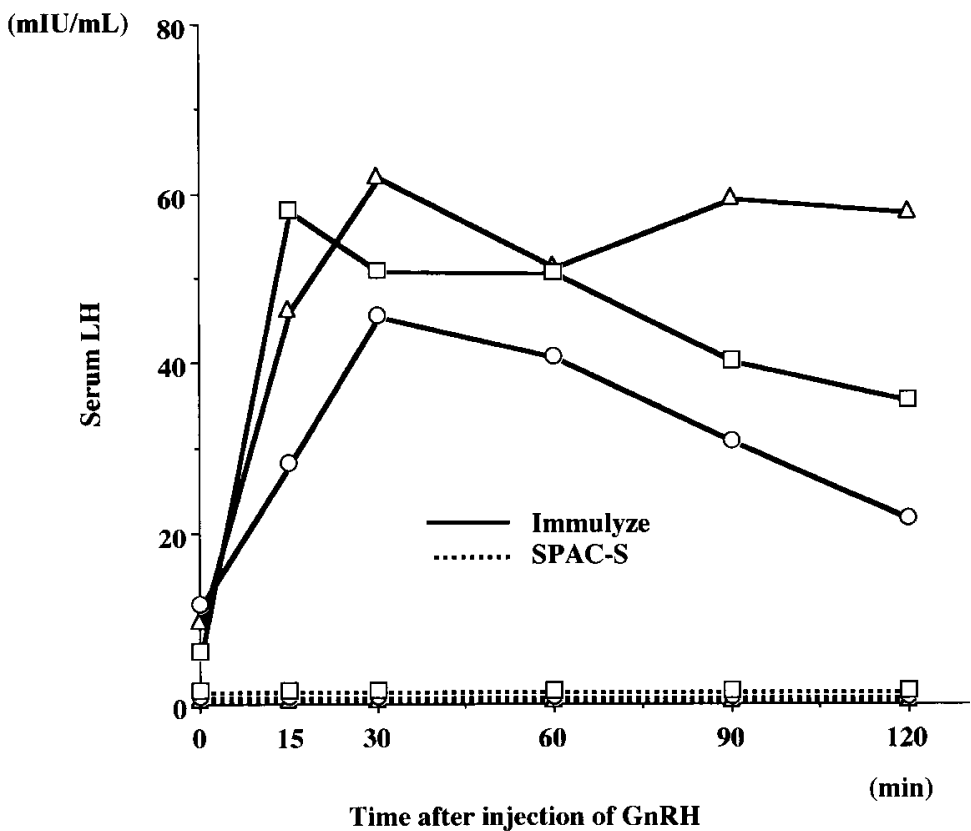

Figure 1 Response of serum $\mathrm{LH}$ to $\mathrm{GnRH}$ stimulation in three women homozygous for variant $\mathrm{LH} \beta$-subunit, as measured by the Immulyze and SPAC-S methods.

\section{Stimulation test results in women with mutant $L H$ and wild-type $L H$}

In response to GnRH stimulation, the three women homozygous for the variant showed no detectable serum LH by the SPAC-S method over $120 \mathrm{~min}$. However, serum LH concentrations determined by the Immulyze method showed an excessive response resembling that of patients with PCOS (the peak LH concentration is $>40 \mathrm{mIU} / \mathrm{ml}$ and the peak:basal LH ratio is $>2$ on the GnRH test), reaching a peak 15-30 min after GnRH injection (Fig. 1).

Responses of serum LH to GnRH stimulation in women with the wild-type LH $\beta$-subunit are shown in Fig. 2A. All showed a normal LH response, with both assays. Statistical analysis of the mean concentration of the LH as determined by SPAC-S at all times after GnRH injection showed significant increases compared with that before GnRH injection. The mean concentrations of $\mathrm{LH}$ at $30 \mathrm{~min}$ after GnRH injection were significantly different from that before injection and those at 15, 90 and $120 \mathrm{~min}$ after injection. The response curve in the GnRH test as determined by SPAC-S showed LH peaks 30 min after GnRH injection. The LH response pattern as determined by Immulyze strongly resembled that of SPAC-S.

Responses of serum LH to GnRH stimulation in the heterozygotes are shown in Fig. 2B. Five of the women showed normal LH responses by SPAC-S, but had an excessive LH response by Immulyze, resembling that of patients with PCOS (the peak LH concentration is $>40 \mathrm{mIU} / \mathrm{ml}$ and the peak:basal LH ratio is $>2$ on the GnRH test). Mean concentration of the LH as determined by SPAC-S at 30, 60, 90 and 120 min after GnRH injection showed significant increases compared with that before injection. However, as determined by Immulyze, the mean concentration of LH at all times after injection showed statistically significant increases compared with that before injection. The mean concentrations of LH as determined by Immulyze at all times after GnRH injection were significantly greater than those by SPAC-S.

The mean percent increase (means \pm s.E.) changes in the concentrations of LH as measured in serum samples with SPAC-S and Immulyze over time after GnRH stimulation in the heterozygous women is shown in Fig. 3. Statistical analysis of mean percent increases in LH as measured by SPAC-S at 30, 60, 90 and $120 \mathrm{~min}$ after GnRH injection showed them to be significantly different from before injection, whereas statistical analysis of the mean percent increase in LH as measured by Immulyze showed significant differences at 15, 30 and 60 min after GnRH injection compared with that before injection. Furthermore, the mean percent increases in LH as measured by Immulyze at 15, 30 and $60 \mathrm{~min}$ after GnRH injection were significantly greater than those measured by SPAC-S. Thus the mean percent increase in the total LH (LH as measured by Immulyze) at $15 \mathrm{~min}$ after $\mathrm{GnRH}$ injection showed significant increases (fourfold) compared with that before injection, but no statistically significant increases in the wild-type LH (LH as measured by SPAC-S) were observed at 15 min after GnRH injection.

The mean percent decrease changes over time of the LH ratio in the 17 heterozygotes and the 20 women homozygous for the wild-type subunit are shown in Fig. 4. Percent decreases (means \pm S.D.) in the LH ratio after the GnRH injection in the women with wild-type LH showed no statistically significant changes. However, the 
A

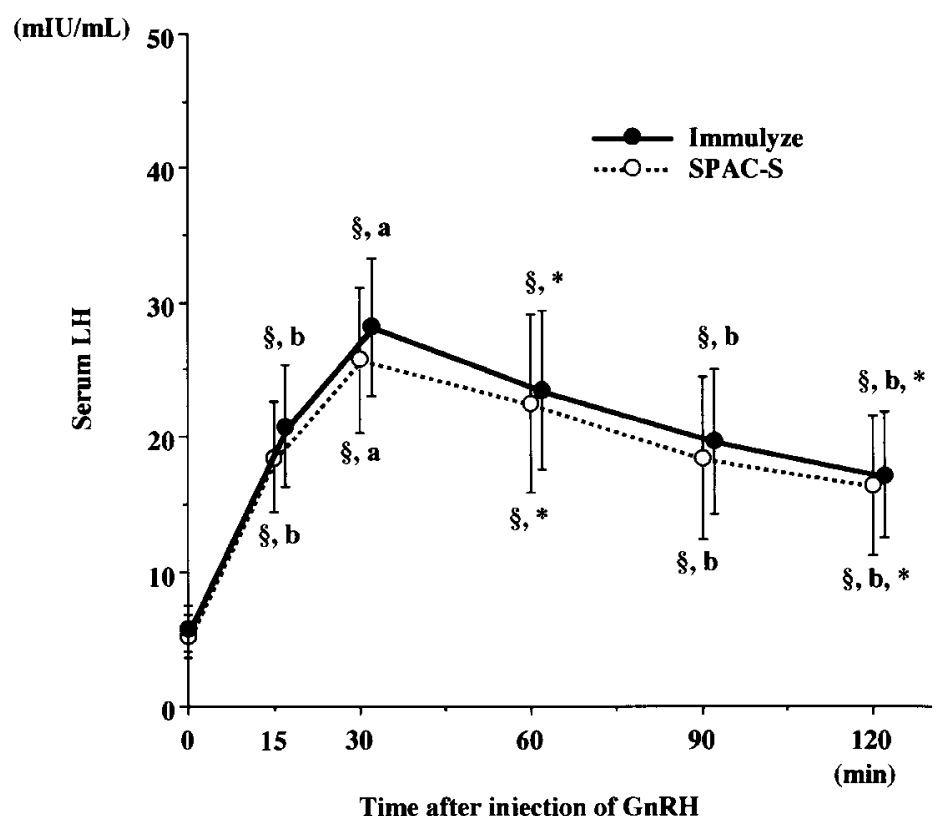

B

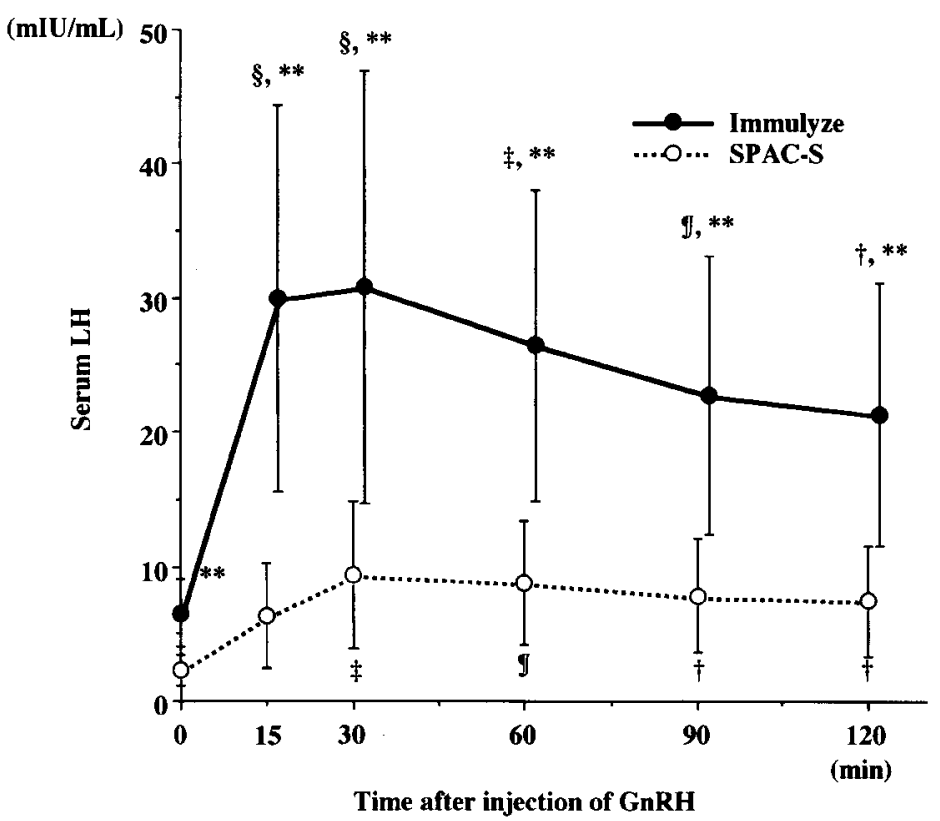

Figure 2 Mean ( \pm S.D.) concentrations of serum LH in the GnRH stimulation test, as measured by the Immulyze and SPAC-S methods. (A) Women with wild-type LH. (B) Women heterozygous for variant $\mathrm{LH} \beta$-subunit. Within a group, values with different superscript letters are significantly different $\left(P<0.01\right.$, ANOVA), and asterisks $\left(^{*}\right)$ denote a pair of mean values that are significantly different $\left(P<0.01\right.$, ANOVA). $\$ P<0.0001, \neq P<0.001, \varangle P<0.01,+P<0.05$ compared with before injection. ${ }^{* *} P<0.001$ compared with LH by SPAC-S. 


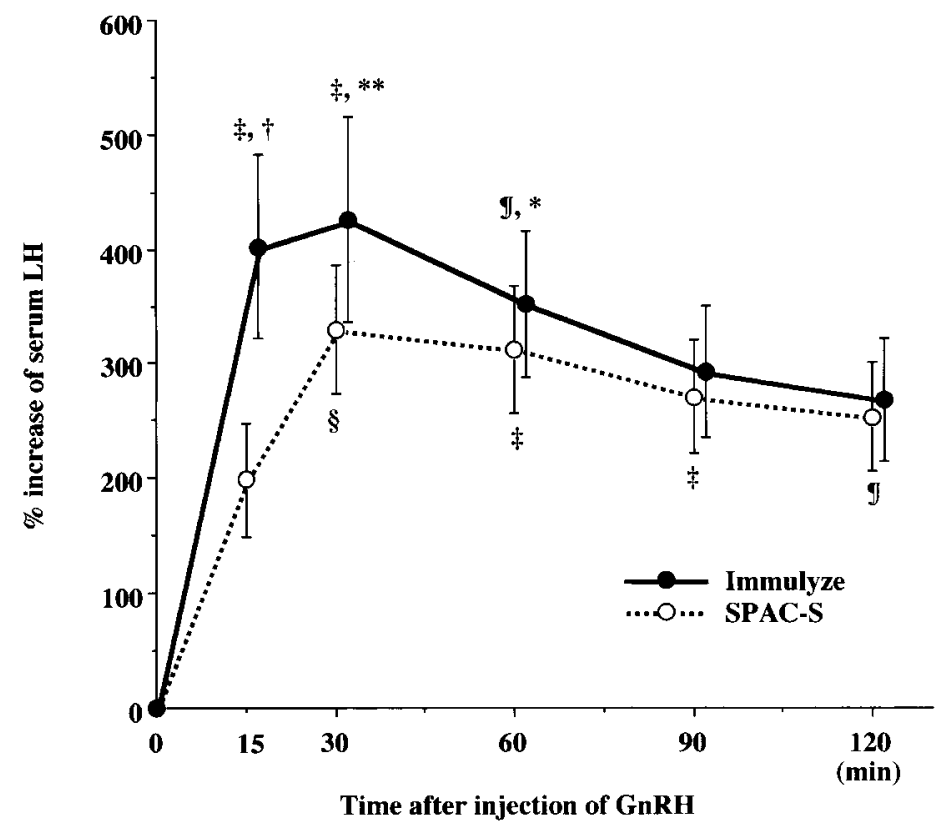

Figure 3 Mean ( \pm S.E.) percent increase in concentration of the $\mathrm{LH}$ as determined by SPAC-S and Immulyze assays in the heterozygous women. $\S P<0.001, \ddagger P<0.01, \uparrow P<0.05$ compared with before injection. $\dagger P<0.001$, ${ }^{*} P<0.01,{ }^{*} P<0.05$ compared with LH by SPAC-S.

mean percent decreases in the ratios in heterozygotes at 15 min after GnRH injection were significantly different from that before injection $(0 \%)$ and those at 30, 60, 90 and $120 \mathrm{~min}$ after injection.

\section{Discussion}

The intact LH monoclonal antibodies of SPAC-S LH that we used do not react with anomalous sites in the $\mathrm{LH} \beta$-subunit that are generated by the point mutation of the LH gene. Accordingly, heterozygous women exhibit low concentrations of serum LH when it is measured by the SPAC-S LH kit. This was proved in our previous report of the absorption test with LH $\beta$-subunit monoclonal antibodies of SPAC-S LH kit (11). Immulyze LH utilizes both an LH $\beta$-subunit monoclonal antibody and an LH polyclonal antibody, thus it can measure both normal LH and variant LH $\beta$-subunit. Heterozygous women have both normal LH genes and anomalous LH genes, because of point mutation. Such women secrete two kinds of LH: wild-type LH and variant LH $\beta$-subunit. If serum LH concentration in heterozygous women are measured by Immulyze LH and SPAC-S LH immunoassay kits simultaneously, the concentration of anomalous

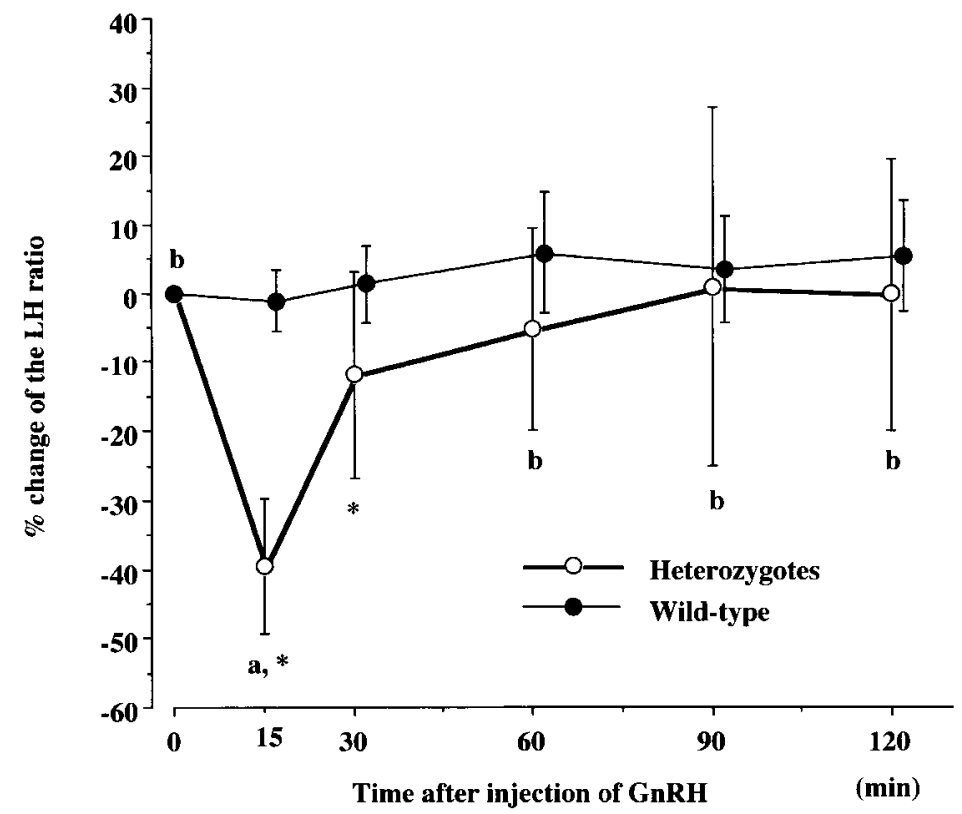

Figure 4 Mean ( \pm S.D.) decrease in LH ratio expressed as a percentage. Within a group, values with different superscript letters are significantly different $(P<0.0001$, ANOVA), and asterisks $\left(^{*}\right)$ denote a pair of mean values that are significantly different $(P=0.001$, ANOVA). 
LH can be calculated by the ratio of the $\mathrm{LH}$ values obtained with the two kits.

We found that the response patterns of serum LH to GnRH injection in women who were heterozygous were different from those in women with wild-type LH. In these heterozygotes, the LH ratio showed a statistically significant decrease at $15 \mathrm{~min}$ after $\mathrm{GnRH}$ injection, essentially returning to baseline at $60 \mathrm{~min}$. In women with wild-type $\mathrm{LH}$, although serum $\mathrm{LH}$ concentrations in the GnRH test peaked at 30 min after GnRH injection, no changes in the response patterns of the LH ratio were evident over $2 \mathrm{~h}$. In heterozygous women, mean percent increase in the total LH (LH as measured by Immulyze) at $15 \mathrm{~min}$ after $\mathrm{GnRH}$ injection showed significant increases compared with that before injection, whereas no changes in the wild-type $\mathrm{LH}$ ( $\mathrm{LH}$ as measured by SPAC-S) concentrations were statistically evident at same time. We therefore hypothesized that the absolute variant LH concentrations also showed a significant increase at $15 \mathrm{~min}$ after $\mathrm{GnRH}$ injection. As the variant LH showed a faster increase and attained greater values than wild-type LH when the pituitary was stimulated by $\mathrm{GnRH}$, the maximal response of the variant $\mathrm{LH}$ to pituitary stimulation with GnRH appears to be greater than that of wild-type LH.

In this study we observed that women who were homozygous for mutant LH $\beta$-subunit showed an excessive LH response in the GnRH stimulation test, similar to the response in patients with PCOS. This observation agrees with results obtained by Suganuma et al. (12). In contrast, among individuals heterozygous for mutant LH, Suganuma et al. (12) found none with an excessive response of serum LH to GnRH injection, whereas we found an increased LH response to GnRH stimulation in five of 17 heterozygotes. However, further investigation in a large number of patients will be necessary to define whether individuals who are homozygous or heterozygous for mutant LH $\beta$-subunit show an excessive LH response in the GnRH stimulation test.

Serum concentrations of a hormone depend on the amount of secreted hormone and the rate clearance of hormone from the circulation. Several studies have examined the clearance of LH in vivo (13-16). Ascoli et al. (13) found that ovine LH is cleared very rapidly from the circulation, with a half-life of 5-15 min, whereas de Krester et al. (14) observed that human LH injected into ewes had a half-life of $23 \mathrm{~min}$. Concerning clearance of the mutant LH, Suganuma et al. (15) anticipated that the mutant LH would be cleared at a slower rate than native $\mathrm{LH}$, as the substitutions of $\operatorname{Trp} 8 \rightarrow \operatorname{Arg}$ and Ile15 $\rightarrow$ Thr were identical to the amino acid differences between LH and hCG; however, they also speculated that mutant LH could have a half-life in vivo similar to that of native $\mathrm{LH}$, as the $\mathrm{LH} \beta$ mutations in the present study did not alter the $\mathrm{COOH}$-terminal structure of $\mathrm{LH} \beta$ to the extent of hCG $\beta$. The $\mathrm{COOH}$-terminus of hCG $\beta$ is believed to be involved in prolonging the plasma half-life of hCG $(16,17)$. In contrast with their speculations, however, these authors found the half-life of mutant LH to be shorter than that of wild-type LH (15). Haavisto et al. (18) also reported the half-life of the variant $\mathrm{LH}$ in homozygotes for the $\mathrm{LH} \beta$ mutations to be significantly shorter than that of wild-type LH in rat circulation. As the oligosaccharides of LH are mostly sulfated (19), Rajkhowa et al. (7) indicated that the observations could be explained by an extra sulfated carbohydrate moiety in the variant $\mathrm{LH}$ molecules, as sulfated carbohydrates are known to be eliminated from the circulation more rapidly by more avid binding to specific hepatic receptors $(20,21)$; however, no clear explanation has been found as to why mutant $\mathrm{LH}$ would be cleared more rapidly than native LH. From the data from the present study and those summarized by several other investigators, we speculate that the pituitary gland in heterozygotes for the mutant LH $\beta$-subunit shows more abundant stimulated secretion of variant LH than wild-type LH.

Many investigators have studied the bioactivity of variant $\mathrm{LH}$, with contradictory results. Using in vitro methods, Furui et al. (1) have reported that the mutant LH showed bioactivity identical to that of wild-type LH and have suggested that the variant may represent biologically silent polymorphism. Similarly, Okuda et al. (22) have reported a woman who had inherited variant LH with normal bioactivity. However, other studies (6, 7, 18) have described in vivo bioactivity of the LH variant as lower than that of the wild-type hormone. Furthermore, Raivio et al. (6) found that the integrated overall effect of LH was lower in individuals with the variant LH than in wild-type homozygotes. Conversely, some in vitro studies have found variant LH from homozygous individuals to have greater bioactivity than $\mathrm{LH}$ from those with the wild-type $(15,18)$. An increase in glycosylation has been shown to enhance the in vitro activity of $\mathrm{LH}$ by increasing $\mathrm{LH}$ action at the receptor site $(23,24)$.

As an additional finding, Jiang et al. (25) have recently studied whether additional mutations in the variant $\mathrm{LH} \beta$ promoter sequence could contribute to the altered physiology of the LH variant molecules. The variant $\mathrm{LH} \beta$ promoter has greater basal activity, and differs in its response to hormonal stimulation, as compared with the wild-type $\mathrm{LH} \beta$ promoter. The altered promoter function of the variant $\mathrm{LH} \beta$ gene provides evidence for differences in regulation of the wild-type and variant $\mathrm{LH} \beta$ genes, which may contribute to the differences in pituitary-gonadal function observed between carriers of the two $\mathrm{LH} \beta$ alleles. The findings also suggest a novel evolutionary mechanism whereby polymorphic changes resulting in altered bioactivity of a gene product may be compensated for by additional mutations in the cognate promoter sequence, changing transcription of the same gene. These findings may explain why our present studies indicated differences in circulatory kinetics between the two LH forms and in 
regulation of the two types of $\mathrm{LH} \beta$ genes. However, further clinical and experimental studies are necessary to clarify whether the presence of variant LH predisposes to reproductive disease, including infertility and ovulatory disorders, as our study population consisted of only 40 women with regular menstrual cycles and variant LH. Furthermore, the biologic effects and clinical significance of variant $\mathrm{LH}$ require much additional investigation.

\section{Acknowledgements}

Supported in part by a grant-in-aid for scientific research from the Ministry of Education of Japan (No. 10671542).

\section{References}

1 Furui K, Suganuma N, Tsukahara S, Asada Y, Kikkawa F, Tanaka M et al. Identification of two point mutation in the gene coding luteinizing hormone (LH) $\beta$-subunit, associated with immunologically anomalous LH variant. Journal of Clinical Endocrinology and Metabolism 199478 107-113.

2 Okuda K, Yamada T, Imoto H, Komatsubara H \& Sugimoto O. Antigenic alterations of an anomalous human luteinizing hormone caused by two chorionic gonadotropin-type aminoacid substitutionds. Biochemical and Biophysical Research Communications 1994200 584-590.

3 Pettersson K, Makela MM, Dahlen P, Lamminen T, Huoponen K \& Huhtaniemi I. Gene polymorphism found in the LH beta gene of an immunologically anomalous variant of human luteinizing hormone. European Journal of Endocrinology 1994130 (Suppl 2) abstract $\mathrm{S} 17.03$.

4 Nilsson C, Pettersson K, Millar RP, Coerver KA, Matzuk MM \& Huhtaniemi IP. World frequency of a common genetic variant of luteinizing hormone: an international collaborative research. Fertility and Sterility 199767 998-1004.

5 Takahashi K, Ozaki T, Okada M, Kurioka H, Kanasaki H \& Miyazaki K. Increased prevalence of luteinizing hormone $\beta$ subunit variant in patients with premature ovarian failure Fertility and Sterility 199571 96-101.

6 Raivio T, Huhtaniemi I, Anttila R, Siimes MA, Hagenas L, Nilsson C et al. The role of luteinizing hormone $\beta$ gene polymorphism in the onset and progression of puberty in healthy boys. Journal of Clinical Endocrinology and Metabolism 199681 3278-3282.

7 Rajkhowa M, Talbot JA, Jones PW, Pettersson K, Haavisto M, Huhtaniemi I et al. Prevalence of an immunological LH $\beta$-subunit variant in a UK population of healthy women and women with polycystic ovary syndrome. Clinical Endocrinology $199543297-$ 303.

8 Takahashi K, Kurioka H, Ozaki T, Kanasaki H, Kohsaka M, Kohji M et al. Increased prevalence of luteinizing hormone $\beta$-subunit variant in Japanese infertility patients. Human Reproduction 1998 $133338-3344$.

9 Odell WD \& Griffin J. Two-monoclonal-antibody 'sandwich'-type assay of human lutropin, with no cross reaction with choriogonadotropin. Clinical Chemistry 198733 1603-1607.
10 Alpert NL. Immulite automated immunoassay system. Clinical Instrument Systems 199313 1-7.

11 Karino K, Shibata H, Takahashi K \& Masuda J. Influence of abnormal structure $\beta$ chain of luteinizing hormone on endocrinological kinetics of luteinizing hormone and gynecological diseases. Japanese Journal of Clinical Pathology 199947 155-159.

12 Suganuma N, Furui K, Furuhashi M, Asada Y, Kikkawa F \& Tomoda Y. Screening of the mutations in luteinizing hormone $\beta$ subunit in patients with menstrual disorders. Fertility and Sterility 199563 989-995.

13 Ascoli M, Liddle RA \& Puett D. The metabolism of luteinizing hormone. Plasma clearance, urinary excretion, and tissue uptake. Molecular and Cellular Endocrinology 19753 21-36.

14 de Krester DM, Atkins RC \& Paulsen CA. Role of the kidney in the metabolism of luteinizing hormone. Journal of Endocrinology 1972 58 425-434.

15 Suganuma N, Furui K, Kikkawa F, Tomada Y \& Furuhashi M. Effect of the mutations (Trp8aArg and Ile15aThr) in human luteinizing hormone (LH) $\beta$-subunit on $\mathrm{LH}$ bioactivity in vitro and in vivo. Endocrinology $1996137831-838$.

16 Braunstein GD, Vaitukaitis JL \& Ross GT. The in vitro behavior of human cholionic gonadotropin after dissociation into subunits. Endocrinology 197291 1030-1036.

17 Matzuk MM, Hsueh AJW, LaPolt P, Tsafriri A, Keene JL \& Boime I. The biological role of the carboxyl-terminal extension of human chorionic gonadotropin $\beta$-subunit. Endocrinology $1975126376-$ 383.

18 Haavisto AM, Pettersson K, Bergendahl M, Virkamaki A \& Huhtaniemi I. Occurrence and biological properties of a common genetic variant of luteinizing hormone. Journal of Clinical Endocrinology and Metabolism 80 1257-1263.

19 Green DE \& Baenziger JU. Asparagine-linked oligosaccharides on lutropin, follitropin and thyrotropin. II. Distribution of sulphated and sialylated oligosaccharides on vovine, ovine and human pituitary glycoprotein hormones. Journal of Biological Chemistry $198826336-44$.

20 Baenziger JU, Kumar S, Brodbeck M, Smith PL \& Beranek MC. Circulatory half-life but not interaction with lutropin/chorionic gonadotropin receptor is modulated by sulphation of bovine lutropin oligosaccharides. PNAS 199289 334-338.

21 Fiete D, Srivastava V, Hindsgaul O \& Baenziger JU. A hepatic reticuloendothelial cell receptor specific for SO4-4GalNAcb1, 4GlcNAcb1, 2 Mano that mediates rapid clearance of lutropin. Cell 199167 1103-1110.

22 Okuda K, Takamatsu J, Okazaki T, Yamada T, Saeki M \& Sugimoto O. Hereditary abnormality of luteinizing hormone resulting in discrepant serum concentrations determined by different assays. Endocrine Journal 199441 639-644.

23 Sairam MR. Role of carbohydrates in glycoprotein hormone signal transduction. FASEB Journal 19893 1915-1926.

24 Wilson CA, Leigh AJ \& Chapman AJ. Gonadotropin glycosylation and function. Journal of Endocrinology 1990125 3-14.

25 Jiang M, Pakarinen P, Zhang FP, El-Hefnawy T, Koskimies P, Pettersson $\mathrm{K}$ et al. A common polymorphic allele of the human luteinizing hormone beta-subunit gene: additional mutations and differential function of the promoter sequence. Human Molecular Genetics 19998 2037-2046.

Received 16 March 2000

Accepted 17 May 2000 